\title{
A discreta e sedutora "História das mulheres" "
}

\section{Diogo da Silva Roiz ${ }^{* *}$}

As mulheres conquistaram o direito de terem a sua história também escrita no século XX. A "história das mulheres" é hoje um campo de pesquisa consolidado em universidades do mundo todo (ainda que em cada país ocorram níveis diferenciados de desenvolvimento e aceitação do campo). Percebe-se, cada vez mais, que a mulher não apenas tem história, mas também fez e faz (a sua) história. De um lado, a conquista do direito ao voto, ao trabalho (e a uma carreira profissional), a uma igualdade de direitos entre os sexos, portanto, buscados com afinco pelos movimentos feministas, a partir do início do século $\mathrm{XX}$, deram margem aos estudos produzidos (em maior escala) - a partir dos anos de 1960. De outro, com os movimentos de massa daquela década, que repercutiram em todo o mundo, ganhando ainda maior repercussão com os movimentos estudantis de "Maio de 1968", vieram também a justificar ainda mais os estudos sobre a mulher, principalmente, com a abertura dos campos de pesquisa produzidos nos anos de 1970.

Mas nem sempre foi assim. Pelo contrário, durante muito tempo as mulheres, e a escrita de sua história, foi um tema opaco e sem sentido, particularmente para pesquisadores do sexo masculino. Tanto nas fontes, quanto nas pesquisas, o que se via

\footnotetext{
* Resenha do livro de Michelle Perrot, As mulheres ou os silêncios da história, 2005. Recebida para publicação em dezembro de 2007, aceita em março de 2008.

** Mestre em História pela UNESP, Campus de Franca. Coordenador do curso de História da Universidade Estadual de Mato Grosso do Sul (UEMS), Campus de Amambai.diogosr@yahoo.com.br
}

cadernos pagu (30), janeiro-junho de 2008:445-452. 
A discreta e sedutora "História das mulheres"

era o silêncio, delas e sobre elas, que se prolongava ainda mais com a escassez de documentos, os quais, quase sempre, não demonstravam a sua presença. $\mathrm{O}$ que torna imprescindíveis os seguintes questionamentos: Como a mulher começou a aparecer nos estudos históricos como tema de pesquisa? O que é a "história das mulheres"? Quais os procedimentos e documentos mais adequados para perceber sua presença na história? Porque é importante escrever a "história das mulheres"?

Por mais de três décadas, a historiadora Michelle Perrot, uma das maiores estudiosas desse tema na França (e reconhecida no mundo todo), sentiu-se incomodada (e inspirada) por esses questionamentos, geralmente efetuados por colegas do sexo masculino, que a levaram a se engajar política e intelectualmente nesse projeto de escrita de uma "nova" história, onde as mulheres fossem incluídas (por direito e por importância) e não ficassem mais em silêncio.

Fruto direto dessas pesquisas, As mulheres ou os silêncios da História reúne parcela significativa de sua contribuição sobre o tema. Ao longo de seus 23 capítulos $^{1}$ publicados entre 1974 e 1998 em revistas especializadas e em livros, a autora passa em revista as principais pesquisas, abordagens e documentos (pesquisados) sobre a "história das mulheres". Aí incluindo sua trajetória no interior desses debates (em que esteve desde o final da década de 1960) e sua contribuição para o tema, em que ainda se destaca a obra A história das mulheres no Ocidente (publicada originalmente entre 1990 e 1992), organizada em cinco volumes com Georges Duby (e a contribuição de outros pesquisadores $e$ pesquisadoras) entre o final dos anos de 1980 e início dos anos de 1990.

De forma didática, a autora dividiu a obra em cinco partes: a) na primeira, Traços, em que aparece a discussão de diários e correspondências do século XIX (por ela pesquisados), em quatro

1 A edição francesa conta com 25, mas a tradução brasileira da obra não conseguiu a concessão de direitos para a publicação de dois ensaios. 
capítulos (29-146), nos quais, segundo ela, a "dificuldade da história das mulheres deve-se inicialmente ao apagamento de seus traços, tanto públicos quanto privados"; b) na segunda, Mulheres no trabalho, principalmente o do lar e o das fábricas, com seis capítulos (149-258), em que, segundo ela, a "questão do trabalho constituiu um front pioneiro da pesquisa sobre as mulheres"; c) na terceira, Mulheres na cidade, apresenta-se sua ação na política $e$ nos debates sobre gênero, cidadania e direitos, em cinco capítulos (261-360), que segundo a autora,

a história das mulheres interessou-se inicialmente por seus papéis privados, observando-os, de certa forma, lá onde elas estavam, em seus corpos, sua casa, seus gestos cotidianos, correndo o risco de fechá-los em uma repetição (...) [mas] a questão do poder colocou-se rapidamente, pois ela funda a relação entre os sexos (261);

d) na quarta, Figuras, Perrot estuda o perfil de Flora Tristan e George Sand, em dois capítulos (363-424), tendo em vista que:

Flora Tristan e George Sand não gostavam muito uma da outra. Elas se impacientavam com seus respectivos comportamentos. Flora invejava George, que já era célebre, enquanto ela penava para poder publicar. George se irritava com as recriminações de Flora. Na verdade, estas contemporâneas mal se cruzavam. Flora morreu em $1844 e$ George, trinta e dois anos mais tarde (1876). No entanto, diversos traços as aproximam, a ponto que se pôde falar de 'vidas no espelho': sua revolta contra a condição das mulheres, que ambas experimentaram na carne; sua vontade de justiça social (...) sua idêntica preocupação com a moral em política (363);

e) finalmente, na quinta parte, Debates, ela apresenta alguns dos principais debates e abordagens sobre o tema, ao longo de seis capítulos (427-503), que avaliam, principalmente, as obras de 
A discreta e sedutora "História das mulheres"

Georges Duby, Mona Ozouf e Michel Foucault, pois, como diz a "história 'das mulheres' coloca numerosas questões, a começar por seu título, constituindo as mulheres em objeto (...) [que] é também um tanto fragmentado" (427-8).

O livro é, portanto, uma exposição amadurecida e articulada, por mais de trinta anos, sobre o que é, e como deve e pode ser feita, a "história das mulheres". Mas para poder atingir todos os objetivos almejados na obra, a autora diz que, antes, foi necessário definir por que houve tamanho silêncio sobre a questão, e como o tema passou a ser de interesse de pesquisadoras no mundo todo. Para ela,

a irrupção de uma presença e de uma fala feminina em locais que lhes eram até então proibidos, ou pouco familiares, é uma inovação do século 19 que muda o horizonte sonoro. Subsistem, no entanto, muitas zonas mudas $e$, no que se refere ao passado, um oceano de silêncio, ligado à partilha desigual dos traços, da memória $e$, ainda mais, da História, este relato que, por muito tempo, 'esqueceu' as mulheres, como se, por serem destinadas à obscuridade da reprodução, inenarrável, elas tivessem fora do tempo, ou ao menos fora do acontecimento (9).

Isso quer dizer que durante muito tempo

as mulheres [foram] mais imaginadas do que descritas ou contadas, e fazer a sua história é, antes de tudo, inevitavelmente, chocar-se contra este bloco de representações que as cobre e que é preciso necessariamente analisar, sem saber como elas mesmas as viam $e$ as viviam (11).

De acordo com ela, esse

....defeito de registro primário é agravado por um déficit de conservação dos traços. Pouca coisa nos arquivos públicos, 
destinados aos atos da administração e do poder, onde as mulheres aparecem apenas quando perturbam a ordem, o que justamente elas fazem menos do que os homens, não em virtude de uma natureza rara, mas devido à sua fraca presença, à sua hesitação também em dar queixa quando elas são as vítimas. Conseqüentemente, os arquivos de polícia e de justiça, infinitamente preciosos para o conhecimento do povo, homens e mulheres, devem ser analisados até na forma sexuada de seu abastecimento" (12).

Por outro lado, diz a autora, "a consideração crescente da vida privada, familiar ou pessoal, modificou o olhar negligente que se tinha sobre as correspondências ou os diários íntimos" nos estudos históricos. No entanto, o

volume e a natureza das fontes das mulheres e sobre as mulheres variam conseqüentemente ao longo do tempo. [Por isso] longe de ser fruto do acaso, a constituição do Arquivo, da mesma forma que a constituição ainda mais sutil da memória, é o resultado de uma sedimentação seletiva produzida pelas relações de força e pelos sistemas de valor $[e$ o] mesmo ocorre no que concerne à narrativa histórica, outro nível destes silêncios encaixados uns nos outros (14).

Não era por acaso que a autora se questionasse como esse silêncio foi rompido e, em seguida, se debruçasse em como as coisas aconteceram na França, lugar onde ela atua como pesquisadora do tema desde a década de 1960. Como esclarece, em cada país houve especificidades quanto ao desenvolvimento $e$ a valorização dos estudos sobre a mulher. No caso da França, foi fundamental a contribuição da obra pioneira de Georges Duby, a partir dos anos de 1970. No campo das Ciências Humanas, os estudos sobre o sexo e a sexualidade humana também foram centrais para o desenvolvimento deste campo de pesquisa. De acordo com ela, três fatores foram fundamentais: a) os científicos "ligados à crise dos grandes paradigmas explicativos e à 
A discreta e sedutora "História das mulheres"

renovação dos contatos disciplinares nas décadas de 1960-70"; b) os sociológicos, em função da

feminização da universidade, inicialmente no nível do público, e depois, mais tardiamente, dos professores, favoreceu o nascimento de novas expectativas, de questionamentos diferentes, e conseqüentemente $\mathrm{o}$ desenvolvimento de cursos e pesquisas sobre as mulheres. As paixões e os interesses se conjugam, de maneira mais clássica, na constituição de um novo "campo" (17);

c) e os políticos, pois, "o movimento de liberação das mulheres - o MLF - surgido nos anos 70 dos silêncios (mais um deles) de Maio de 1968 sobre as mulheres". Nesse sentido, Perrot indica sua própria trajetória e como percorreu esses caminhos na França, no decorrer de suas pesquisas. Em suas palavras:

Experiência insubstituível para aquelas $e$ aqueles que a fizeram, a história das mulheres (...) [no entanto] não mudou nem a atitude histórica, ainda reservada, nem as instituições universitárias, que se opõem a lhe dar um lugar, ainda que modesto. Os inevitáveis conflitos de território conduzem às vezes a tensões, internas e externas aumentadas, e cuja conta pode vir a ser paga pelas pesquisadoras mais jovens. E a França, sob este ângulo, parece mais arcaica do que a maioria de seus vizinhos. A história das mulheres também não mudou muito o lugar ou a "condição" destas mulheres. No entanto, permite compreendê-los melhor. Ela contribui para sua consciência de si mesmas, da qual é certamente ainda um sinal (26).

Assim, compreender, os percalços que ainda subsistem na pesquisa que empreende a escrita da história das mulheres não é uma tarefa nada fácil. Ao percorrer, no século XIX, as razões que levaram aos silêncios sobre as mulheres e, parcialmente, inviabilizaram a escrita de sua história, indica que: 
Da História, a mulher é diversas vezes excluída. Ela o é, inicialmente, na narrativa, que, passadas às efusões românticas, constitui-se como encenação dos acontecimentos políticos. $\mathrm{O}$ positivismo opera um verdadeiro refluxo no tema feminino e, mais amplamente, no cotidiano. O austero Seignobos, grande mestre dos estudos históricos na Universidade, expulsa Eva, ao passo que as paredes da Sorbonne cobrem-se de afrescos em que flutuam diáfanas alegorias femininas (...). A "profissão de historiador" é um trabalho de homens que escrevem a história no masculino. Os campos que eles abordam são os da ação e do poder masculino, até mesmo quando eles se aventuram por novos territórios (...). Também - e esta é a segunda volta da chave - os materiais utilizados pelos historiadores (arquivos diplomáticos, ou administrativos, documentos parlamentares, biografias ou publicações periódicas...) são o produto de homens que têm $\mathrm{o}$ monopólio da escrita tanto quanto da coisa pública (...). Essa exclusão é, aliás, apenas a tradução, redobrada, de uma outra exclusão: a das mulheres da vida e do espaço público na Europa Ocidental no século XIX (197-8).

Para ela, uma exceção no século XIX sobre essa questão foi Jules Michelet, que empreendeu uma exaustiva pesquisa sobre a feitiçaria. Ressalta que as raras exceções de pesquisa e trabalhos sobre a mulher no período se devem ao próprio tipo de temas e abordagens então praticados nos estudos históricos que inviabilizavam a presença feminina no processo histórico e a percepção de sua existência.

Por outro lado, Perrot observa como a sociedade (entendida aqui no masculino) se preocupava em pensar o que era $\mathrm{o}$ "trabalho de mulher":

Os homens do século 19 europeu tentaram, de fato, isolar a força crescente das mulheres, tão fortemente sentida na era das Luzes e nas Revoluções, cujas infelicidades lhes seriam muitas vezes atribuídas, não somente enclausurando-as em 
A discreta e sedutora "História das mulheres"

casa, e excluindo-as de certos domínios de atividade - a criação literária e artística, a produção industrial e as trocas, a política e a história - mas também, e ainda mais, canalizando sua energia para o doméstico revalorizado, $e$ até mesmo para o social domesticado (279).

Para ela, a "história das mulheres escreve[u]-se inicialmente sobre o modo da exceção: exceção das pioneiras que quebram o silêncio". Por isso, é possível entender porque ao longo de muitos destes ensaios, a autora volta a ressaltar incansavelmente os tipos de silêncio impostos às mulheres do passado - e a escrita de uma história das mulheres no século XX - enfatizando os detalhes, como os olhares sobre o corpo feminino, os espaços de fala $e$ debates femininos, e a função da política, da cidadania e das guerras sobre a ação feminina. Por isso também, se preocupa tanto em equacionar os debates sobre a "história das mulheres" $e$ os avanços alcançados pelas pesquisas ao longo do tempo. Em função de todas essas qualidades, este livro é uma bela contribuição para o tema, tema este que está em permanente processo de construção. 